2019 IEEE International Conference on Industrial Engineering \& Engineering Management
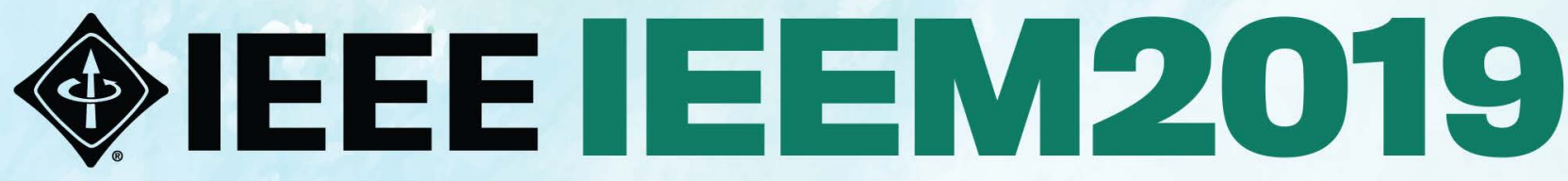

15-18 Dec, Macau

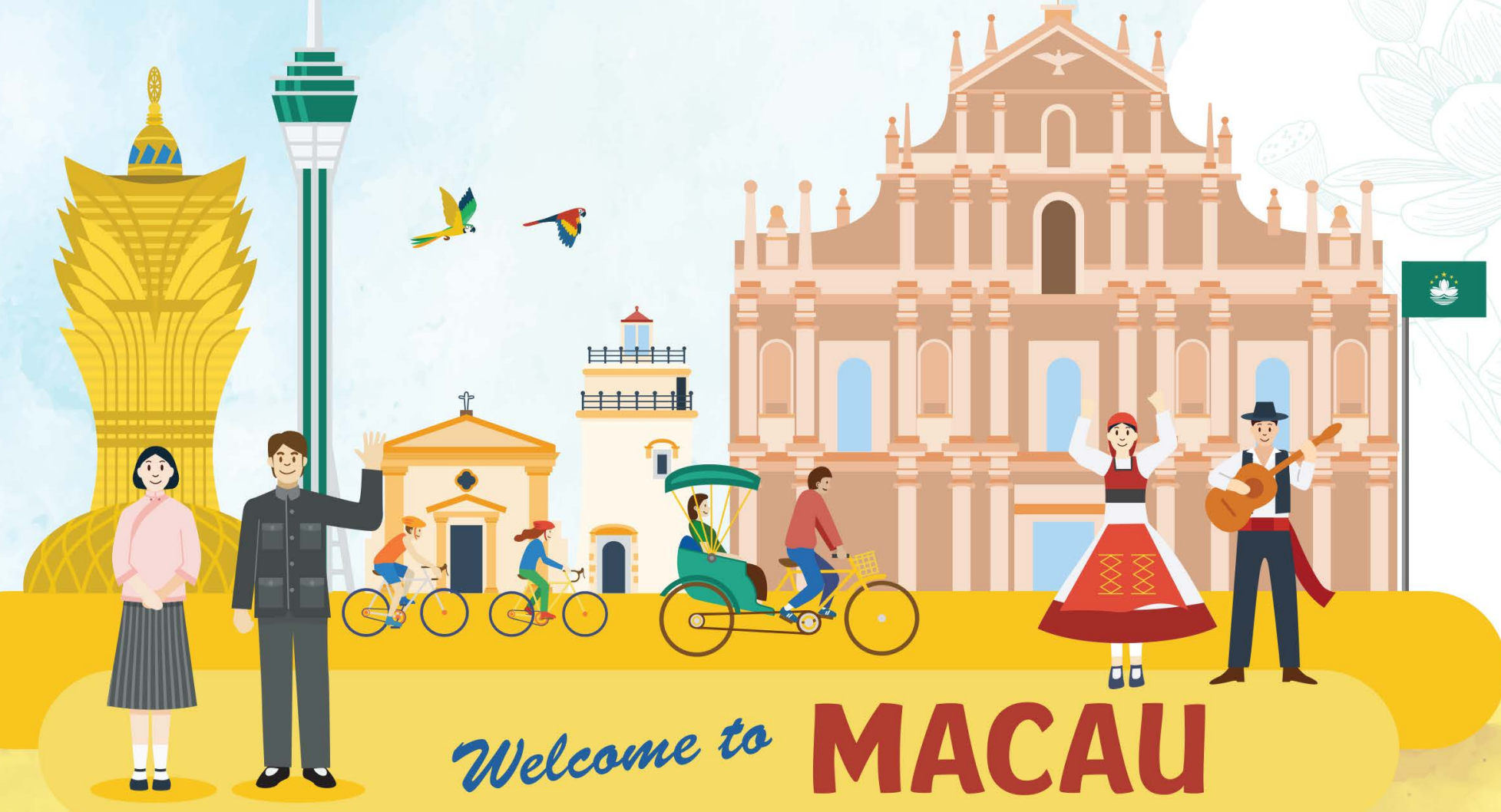


IEEE Catalog Number: CFP19IEI-ART

ISBN: 978-1-7281-3804-6

Copyright and Reprint Permission: Abstracting is permitted with credit to the source. Libraries are permitted to photocopy beyond the limit of U.S. copyright law for private use of patrons those articles in this volume that carry a code at the bottom of the first page, provided the per-copy fee indicated in the code is paid through Copyright Clearance Center, 222 Rosewood Drive, Danvers, MA 01923. For reprint or republication permission, write to IEEE Copyrights Manager at pubs-permissions@ieee.org. All rights reserved. Copyright $(0) 2019$ by IEEE. 


\title{
The Profile of Forthcoming Quality Leaders: An Exploratory Factor Analysis
}

\author{
J.P.T. Domingues ${ }^{1,2}$, F.D. Correia ${ }^{1,2}$, I. Uzdurum ${ }^{1,2}$, P. Sampaio ${ }^{1,2}$ \\ ${ }^{1}$ Department of Productions and Systems, University of Minho, Braga, Portugal \\ ${ }^{2}$ ALGORITMI Research Centre, School of Engineering, University of Minho, Portugal
}

\begin{abstract}
Currently, due to the globalization phenomenon and technological evolution, we are facing a new challenging set of paradigms encompassing social, industrial, financial and cultural issues. Hence, it is a difficult task to anticipate the new demands of the market concerning the most appreciated skills in the forthcoming workforce. This paper intends to report the sets of skills that comprise the desirable profile of the quality professional in the $21^{\text {st }}$ century. To meet this purpose, a worldwide online survey was held online throughout the first quarter of 2018, assessing (adopting a 5-point Likert scale) the importance of 27 skills identified in relevant literature. A total of 319 valid answers, originated from 61 different countries, were collected and summarized through descriptive statistics. The results suggest that seven sets of skills (appreciated skills to forthcoming quality professionals) comprise the profile of the quality professional in the $21^{\text {st }}$ century. Thus, professionals aiming the quality leader role may now tailor their skills based on the information provided in this paper. In addition, companies can use these results to specify the dimensions that their human resources should develop.
\end{abstract}

Keywords - Quality Leader Profile, Professional Skills, $21^{\text {st }}$ century, Worldwide Survey

\section{INTRODUCTION}

\section{A. Emerging Concepts and Change}

In a globalized world, "skills" is the key word to survive. With the emergence of new needs and expectations, costumer's awareness has increased, and competition has become severe with technology emerging at an astonishing rate [1]. In fact, the ideal employee is desired by all organizations, however one may ask "Which dimensions should encompass the profile of a valuable employee?". Due to cultural and organizational strategies and objectives, this seems to be an ever changing variable. Nevertheless, some abilities are common and can differentiate a valuable professional from an average one. Frequently, managers think of a valuable professional as that one promoting organizational growth, financial return and company's costs reduction [2]. These correspond to the fundamental skills that any company will expect from a new employee and now (at the dawn of a new millennium) seems the proper time to think of what makes us different and what companies are looking for. Thus, conducting studies that point out the crucial skills that employees must encompass so they can meet success, is as fundamental as understanding the new emergent terms in industry [3]. This study was carried out aiming at understanding and establishing the skills that a valuable quality professional must held in the $21^{\text {st }}$ century. Usually a gap emerges when comparing what quality professionals put into practice and what companies actually expect from them (a misconception between what is perceived and what is real) [4]. Nowadays, several new topics emerge across industry such as industry 4.0, learning factories, internet of things and digitization [5]. Given the novelty that arises from these trends the quality professionals must adapt to a changing world and should develop the proper skills which will allow them to deal with such challenges. Quality professionals will, inevitably, follow the trend through digitized technologies and new tasks will emerge, as displayed in Table I.

TABLE I

Tasks performed by employees in digitized technologies (retrieved from [6])

Activity Description

Specification of Setting up and digitizing of identification codes for production order product parts and relevant types of production operations; Creating digital bindings of the "product - manufacturing process" Providing comprehensive digital inputs and outputs

Production Identification, setting up and standardization of the portfolio collaborative platform for the digitally controlled management by manufacturing process; Flexible simulation of the production cell production process; Database of availability and performance parameters of production technologies

Production Setting up and standardizing the platform and planning and procedures for digital decision making;

scheduling

Flexible job Multi-level, digitally organized production organization scheduling in real time; Organization and administration of data analytics in real time Creating online error identification and fault elimination

Production Online Workplace Performance Monitoring process Scheme; Optimizing material and information realization flows; Digital management of production processes Customer Setting up a digital protocol for testing the quality satisfaction of the manufactured product, the production process being carried out; Creation of digitally controlled process improvement systems

With the emergence of these tasks (Table I), it seems that this research topic- The profile of the Quality professionals in the $21^{\text {st }}$ century- is an important and needed contribution to the field of quality aiming at understanding whether quality professionals are ready or not to face the challenges posed by this new industrial paradigm.

\section{B. Professional skills in a turbulent and ever-changing context}

In the $21^{\text {st }}$ century's competitive environment, it is important that companies understand these new trends and 
take advantage of them [7]. Technology is changing at a fast pace and Industry 4.0 emerged shedding light on a new industrial revolution [8]. Within the topic of Industry 4.0 one should highlight what is defined as Quality 4.0, i.e., the successful integration and synchronization of procedures, production and processes (the bottom line of quality management in this new industrial paradigm) [9]. Quality 4.0 encompasses the digital transformation of management systems and product/service compliance by incorporating digitalization and related technology and, thus, changing the working roles as shown in Figure 1 [10].

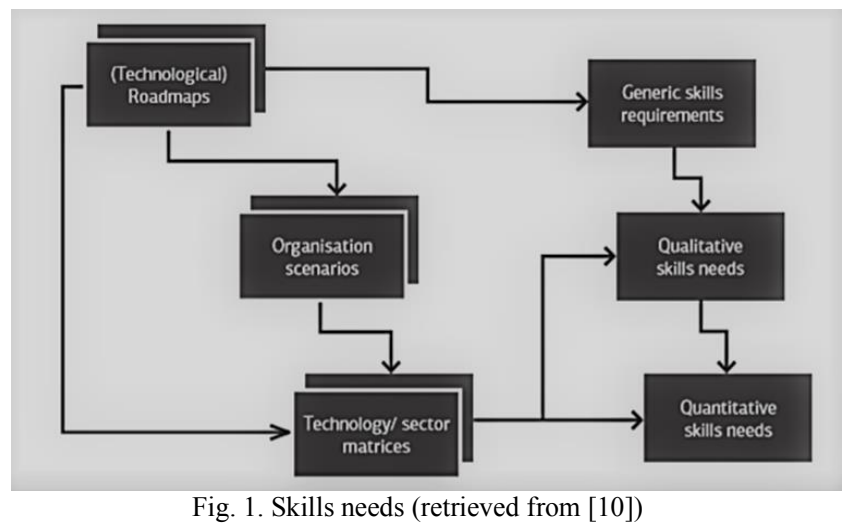

It is of the utmost importance that quality professionals are accurately informed about the developments in quality management, the implications of those developments and their role in this new age [11]. Each quality employee should learn about Industry 4.0 (a.k.a. Education 4.0) and Quality 4.0, contributing to the improvement of their profile as quality professionals [12]. In addition to these technological advances, in recent years, social responsibility emerged as a commonly addressed topic due to global changes. Social responsibility is no longer seen as a tool to attain credibility, but as an effective target and "Doing well by doing good" is being adopted by an increasing amount of organizations [13]. On this note, one should stress that in 2009, the American Society for Quality pointed out some new career paths for quality professionals, such as: systematic measurement for sustainable results; operational efficiency and cost savings; consumer preference for green products and services and regulatory standards focused on ethical behaviour [14].

\section{Skills and Skills Gaps}

In an industrial context, there are several skills that are required regardless the position one apply for, commonly classified as soft skills [15]. On the other hand, there are many specific skills that are needed so one can be effective doing our work, being these classified as hard skills [16]. These two types of skills complement each other being of the utmost interest to find a perfect match of both in order to succeed-in the quality field in what matters to this study.
The scientific community is already putting some effort in this topic, as some studies are already being conducted as an attempt to introduce these new skills in student's courses, directing their behavior towards a global approach [17]. Toddi Gutner and Mike Adams identified some skills in 'The Conference Board's Quality Council' and Jiju Antony presented the various existing perspectives concerning the future of quality professionals sustained on the opinions of a panel comprised by academics and practitioners selected from different countries [18]. A major insight was that rather than controlling and improving, quality professionals will focus on value creation and on innovative activities. In addition, these professionals will work more closely with customers and suppliers aiming at the establishment of a more effective supply chain. The authors also sustained that the forthcoming quality professionals must be aware of maintainability, reliability and serviceability of products, lean six-sigma, systems thinking and management for change. In fact, holding personal skills are crucial factors in business life to create value. In addition, these skills are of utmost importance to successfully translate knowledge into results and to increase quality of life.

Non-technical skills can be developed with experience and long-term practice, not in the short run [3]. Conversely, technical skills are associated with employees' domain of work, technical competence or expertise. To develop technical skills, there are some techniques, such as: courses, seminars, technical certification and internet [19]. Non-technical skills are essential for skilled employees to balance their technical skills. Today, organizations are looking for employees who hold both technical and non-technical skills [20, 21]. However, there still exists a gap between perceived skills and skills put into practice. This may be explained by the fact that one base convictions in information that does not match reality. Thus, new skills must be considered and evaluated in terms of importance to quality professionals. Based in this need, the research team presents a new set of skills supported on the results collected in a worldwide survey aiming at assessing their importance and relevancy to the current industry.

\section{METHODOLOGY}

A worldwide online survey- previously validatedwas held between April and September of 2018 aiming at the importance assessment (5-point Likert type scale: 1Unimportant...5- Extremely important) of 27 skills potentially relevant to the Quality manager/leader role and previously identified through an extensive and comprehensive literature review.

Exploratory factor analysis (EFA) was adopted to identify/extract the latent factors/components. The exploratory factorial analysis establishes the correlation of observable variables and organizes them into factors, which in themselves are unobservable variables. Thus, it is able to make a complex study simpler, reducing a large 
number of variables correlated into few factors. In more detail:

- In the first step of the research (Literature Review), a comprehensive literature review was carried out addressing skills, quality professionals' profile and new trends in industry;

- In addition, the "Development of questionnaire" stage encompassed the questionnaire-online survey design, conception and development. The literature review pointed out several skills and, for the purpose of this research, the platform provided by University of Minho (Lime Survey) was adopted to develop the online questionnaire. The survey structure comprised two sections. Section 1 encompassed 11 questions (both individual and company based) intended to ascertain the profile of the respondents. Section 2 was sectioned into two parts. First part included specific questions encompassing 27 expressions addressing the most relevant skills of the quality professionals and second part encompassed three open-ended questions each of them asking the respondents' opinions regarding current skills of quality professionals and quality tools.

Concerning the questionnaire validation one should stress that prior holding the survey online a pilot test was carried out among three experts in the quality area and by five practitioners (selected from the Quality and Organizational Excellence group of University of Minho, Braga). The survey was analyzed by group members and supported on their insights some changes were introduced aiming at the improvement of the survey.

- Finally, the data collected with the dissemination of the survey all over the world was analyzed adopting the IBM SPSS statistical software.

\section{RESULTS}

\section{A. Variables Codification}

In order to analyze the 27 variables that were presented in the survey, the research team adopted a code for each variable, presented in Table II.

TABLE II

Codification of Variables

\begin{tabular}{ccc}
\hline Abbreviation & Code & Skill \\
\hline AbsThought & An1 & Having an abstract thought \\
Ind4.0 & T1 & Being an Industry 4.0 expert \\
QualTools & QO1 & Being an expert on quality tools \\
Troublesh & T2 & Being a troubleshooting expert \\
ITTools & T3 & Being able to work with IT tools \\
EmoInt & C1 & Having emotional intelligence \\
Persuasive & C2 & Being persuasive \\
Innovative & PT1 & Being innovative \\
Altruistic & PT2 & Being altruistic \\
WorkTeams & C3 & Being able to work with teams \\
Ambitious & PT3 & Being ambitious \\
SocNetwork & PT4 & Being able to create social network \\
ComProblSol & Ad1 & Being an expert at complex problem solving \\
ChangRoles & Ad2 & Being able to adapt into changing roles \\
CogFlex & Ad3 & Having cognitive flexibility \\
GoodComm & C4 & Being a good communicator \\
Instructive & QO2 & Being instructive
\end{tabular}

\begin{tabular}{ccc} 
MotWorkers & L1 & Motivating workers \\
Coordinative & L2 & Being coordinative with all departments \\
AbleDelegate & L3 & Being able to delegate \\
FairObjective & L4 & Being fair and objective \\
ModDiff & L5 & Being able to moderate difficulties \\
Congratulate & L6 & Being able to congratulate \\
CustFocused & QO3 & Being customer focused \\
GoodManSkills & L7 & Having good management skills (time \\
management, risk management etc.) \\
AnalyReas & An2 & Being good at analytical reasoning \\
StatTools & An3 & Being capable of adopting statistical tools \\
\hline
\end{tabular}

\section{B. Reliability Analysis}

A reliability analysis was carried out on the perceived importance Likert type scale comprising the 27 items that were assessed by the respondents. Cronbach's alpha showed the questionnaire to reach acceptable reliability $(\alpha=0,90)$ suggesting a high internal consistency and a reliable questionnaire (Table III).

TABLE III

Reliability Analysis

\begin{tabular}{ccc}
\hline $\begin{array}{c}\text { Cronbach's } \\
\text { alpha }\end{array}$ & $\begin{array}{c}\text { Cronbach's alpha based on } \\
\text { standardized items }\end{array}$ & $\begin{array}{c}\text { No. of } \\
\text { items }\end{array}$ \\
\hline 0,901 & 0,904 & 27
\end{tabular}

Additionally, none of the items results in an increase in the alpha if deleted (all items can be retained). Results show that, if deleted, each item will output a decrease in the alpha (or at least in an equal value of alpha).

Exploratory Factor Analysis

A factor analysis (extraction through the maximum likelihood method) of the results was carried out. Bartlett's test of sphericity (testing the overall significance of all the correlations within the correlation matrix) was significant $(\chi 2(351)=2882.76, p<0,001)$, suggesting the appropriateness of using the factor analytic model. The Kaiser-Meyer-Olkin (sampling adequacy) $(\mathrm{KMO}=0,894)$ pointed out the solid (strong) relationships among the variables suggesting that was acceptable to proceed with the analysis (Table IV).

TABLE IV

KMO and Bartlett's test

\begin{tabular}{l|l|c}
\hline Kaiser-Meyer-Olkin measure of sampling adequacy & 0,894 \\
Bartlett's test of sphericity & Approx. Chi-Square & 2882,755 \\
& df & 351 \\
& Sig. & 0,000 \\
\hline
\end{tabular}

As previously stressed, 27 personal and professional skills that may impact on the profile of the $21^{\text {st }}$ century quality leader were analysed using principal component analysis (Varimax rotation). The communalities of each variable (not shown) are acceptable $(>0,5)$ with solely one variable (Being coordinative) having an amount of variance less than $50 \%(47,8 \%)$ in common with the other variables. This suggest that the variables are strongly related among them which is somewhat expected since they should reflect, ultimately, one construct. As previously stressed the KMO and Bartlett's test of 
sphericity both suggest that the set of variables are at least adequately related for factor analysis meaning that seven clear independent patterns were identified (i.e., not correlated patterns).

The analysis yielded seven components explaining a total of $59,41 \%$ of the variance for the entire set of variables (Table $\mathrm{V}$ ). These preliminary results were sent to a group of 11 experts and each of them was asked to label each component. The insights from this group of experts defined the labelling of each component. The first component (explaining 29,11\% of the total variance) was labelled "Leadership Skills" due to the high loadings by the following items: Motivating workers; being coordinative with all departments; being able to delegate; being fair and objective; being able to moderate difficulties; being able to congratulate; having good management skills (time management, risk management, etc.). The second component (explaining 6,93\% of the total variance) was labelled "Personality Traits". This factor was labelled as such due to the high loadings by the following factors: being innovative; being altruistic; being ambitious; being able to create social network. The remaining 5 factors were labelled "Communicational Skills", "Quality Oriented Skills", "Adaptability Skills", "Analytical Skills" and "Technological Skills" (Table V).

TABLE V

Total Variance Explained

\begin{tabular}{|c|c|c|c|c|c|c|c|c|}
\hline \multicolumn{3}{|c|}{ Initial Eigenvalues } & \multicolumn{3}{|c|}{$\begin{array}{l}\text { Extraction Sums of } \\
\text { Squared Loadings } \\
\end{array}$} & \multicolumn{3}{|c|}{$\begin{array}{c}\text { Rotation Sums of } \\
\text { Squared Loadings }\end{array}$} \\
\hline Total & $\begin{array}{c}\% \\
\text { Vari. }\end{array}$ & Cumul. \% & Total & $\%$ Vari. & $\begin{array}{c}\text { Cumul. } \\
\%\end{array}$ & Total & $\begin{array}{c}\% \\
\text { Vari. }\end{array}$ & Cumul. \% \\
\hline 7,860 & 29,11 & 29,112 & 7,860 & 29,112 & 29,112 & 3,137 & 11,618 & 11,618 \\
\hline 1,870 & 6,926 & 36,038 & 1,870 & 6,926 & 36,038 & 2,441 & 9,042 & 20,660 \\
\hline 1,613 & 5,975 & 42,013 & 1,613 & 5,975 & 42,013 & 2,439 & 9,033 & 29,693 \\
\hline 1,337 & 4,952 & 46,965 & 1,337 & 4,952 & 46,965 & 2,276 & 8,430 & 38,124 \\
\hline 1,244 & 4,608 & 51,573 & 1,244 & 4,608 & 51,573 & 2,188 & 8,104 & 46,228 \\
\hline 1,084 & 4,016 & 55,589 & 1,084 & 4,016 & 55,589 & 1,823 & 6,752 & 52,980 \\
\hline 1,032 & 3,823 & 59,412 & 1,032 & 3,823 & 59,412 & 1,737 & 6,432 & 59,412 \\
\hline 0,870 & 3,224 & 62,636 & & & & & & \\
\hline 0,844 & 3,125 & 65,762 & & & & & & \\
\hline 0,785 & 2,909 & 68,670 & & & & & & \\
\hline 0,738 & 2,734 & 71,404 & & & & & & \\
\hline 0,725 & 2,686 & 74,090 & & & & & & \\
\hline 0,653 & 2,417 & 76,508 & & & & & & \\
\hline 0,632 & 2,342 & 78,850 & & & & & & \\
\hline 0,603 & 2,233 & 81,083 & & & & & & \\
\hline 0,592 & 2,193 & 83,276 & & & & & & \\
\hline 0,550 & 2,036 & 85,312 & & & & & & \\
\hline 0,544 & 2,014 & 87,325 & & & & & & \\
\hline 0,473 & 1,753 & 89,078 & & & & & & \\
\hline 0,463 & 1,713 & 90,791 & & & & & & \\
\hline 0,420 & 1,554 & 92,345 & & & & & & \\
\hline 0,397 & 1,472 & 93,817 & & & & & & \\
\hline 0,393 & 1,457 & 95,274 & & & & & & \\
\hline 0,349 & 1,291 & 96,565 & & & & & & \\
\hline 0,340 & 1,261 & 97,826 & & & & & & \\
\hline 0,333 & 1,231 & 99,058 & & & & & & \\
\hline 0,254 & 0,942 & 100,000 & & & & & & \\
\hline
\end{tabular}

In order to ensure the results, the scree plot (Figure 2) was used, showing that from the seventh component onwards the line is almost flat suggesting that each successive component is accounting for not relevant amounts of the total variance (components with eigenvalues less than 1). So, the scree plot depicted in Figure 2 backs up the data from Table $\mathrm{V}$, i.e., it is possible to extract seven components based on the available data.

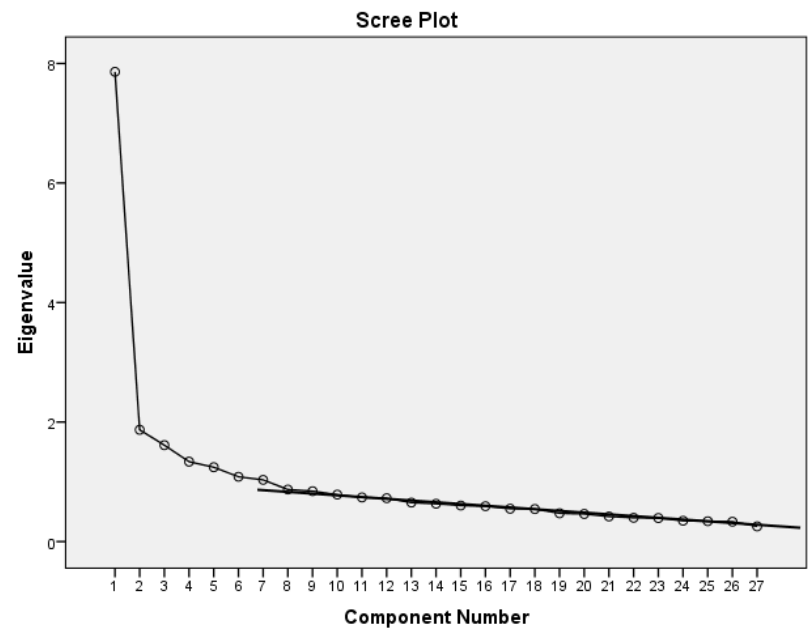

Fig. 2. Scree Plot

The Cronbach alpha (by component) is presented in Table VI. It is possible to highlight that solely the "Quality Oriented Skills" component presents a poor Cronbach Alpha score. At this stage this poor result does not preclude the validity of the component and, later on, throughout the development of the measurement model (CFA) and the structured equation model, it will be assessed if the items comprising this component will be retained or not (the same procedure will be carried out for the other remaining components) taking into account the final fit indexes.

Table VI.

Reliability assessment by component (Cronbach Alpha)

\begin{tabular}{cc}
\hline Component & Cronbach Alpha \\
\hline Leadership Skills & 0,808 \\
Personality Traits Skills & 0,726 \\
Communicational Skills & 0,732 \\
Quality Oriented Skills & 0,570 \\
Adaptability Skills & 0,695 \\
Analytical Skills & 0,707 \\
Technological Skills & 0,593 \\
\hline
\end{tabular}

The rotated component matrix (Table VII) clarifies the number of components and the variables clustered within. It is possible to distinguish seven components and nearly all the variables load highly in solely one factor. However, it is possible to observe some slight cross loadings in the following variables: "Coordinative", "Ambitious", "ChangRoles", "AnalyReas", "StatTools" and "Ind4.0". 
Table VII. Rotated component matrix ${ }^{\mathrm{a}}$

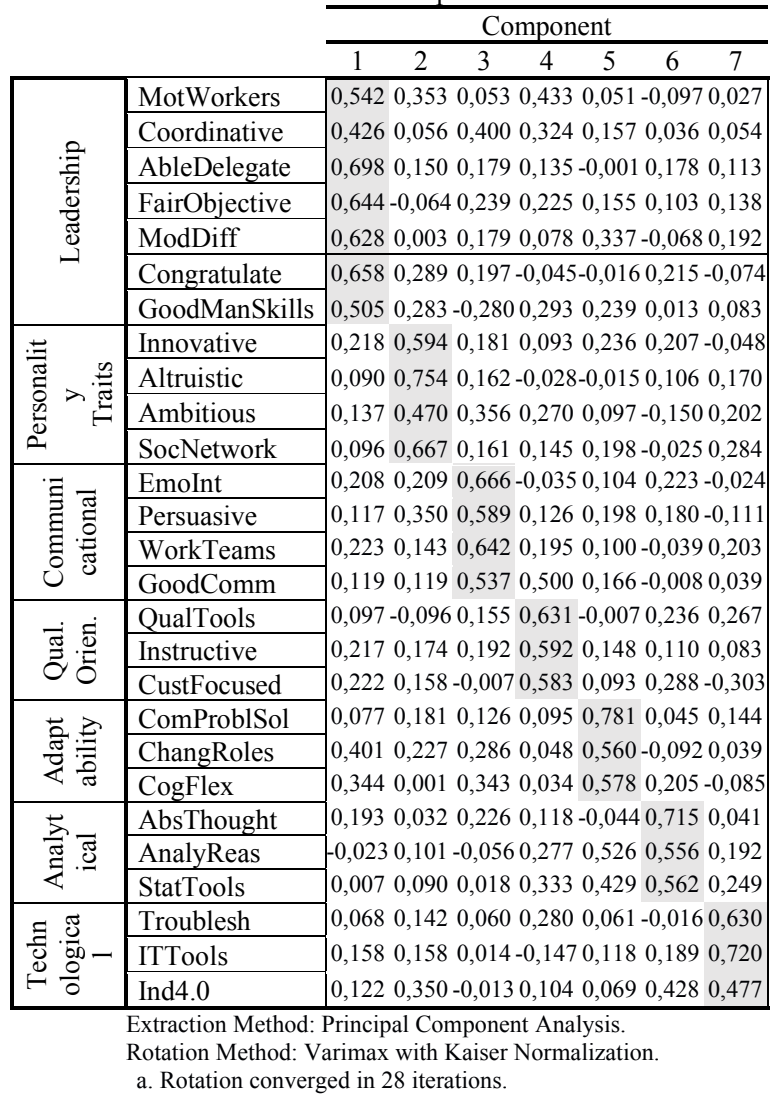

\section{CONCLUSION}

This paper identifies seven significant dimensions that comprise the profile of the quality leader of the $21^{\text {st }}$ century. It provides a better understanding of the relationships established between these dimensions by discovering the most significant influencing factors. The research provides the profile explained in 7 different groups, each one containing specific skills from the 27 identified. This paper pointed out the most appreciated set of skills to forthcoming quality leaders. This fact entails that professionals aiming at the quality leader role in the future may now tailor and develop their skills based on the information provided by this study. Moreover, companies may use the results to specify and optimize which dimensions should be developed in their human resources in order to achieve the highest benefits and outputs.

\section{ACKNOWLEDGMENT}

The authors would like to thank the collaboration of the respondents who kindly answered the survey. In addition, the authors would like to thank ASQ and ALGORITMI Research Centre for disseminating the online survey. This work has been supported by COMPETE: POCI-01-0145-FEDER-007043 and through FCT-Fundação para a Ciência e Tecnologia within the Project Scope: UID/CEC/00319/2019.

\section{REFERENCES}

[1] J. Oakland, "From quality to excellence in the 21st century," Total Qual. Manag. Bus. Excell., vol. 16, no. 8-9, pp. 1053-1060, Oct. 2005 .

[2] M. Monroy and A. L. Zwerling, "The importance of a good employee handbook," J. Am. Coll. Radiol., vol. 11, no. 4, pp. 421422, Apr. 2014.

[3] R. Flin, K.-M. Goeters, and H. Hoermann, Components of nontechnical skills. 1998.

[4] S. Kergroach, "Industry 4.0: new challenges and opportunities for the labour market," Foresight STI Gov., vol. 11, no. 4, pp. 6-8, Dec. 2017.

[5] B. Schallock, C. Rybski, R. Jochem, and H. Kohl, "Learning factory for Industry 4.0 to provide future skills beyond technical training," Procedia Manuf., vol. 23, pp. 27-32, 2018.

[6] F. Chromjakova, "Digital literacy of employees in production process- Analyze of production stability and productivity in INDUSTRY 4.0 concept," in The 6th International Conference on Manufacgtering, Optimazation, Industrial and Material Engineering, 2018, pp. 56-89.

[7] A. Yildiz, "Industry 4.0 and smart factories," Sak. Univ. J. Sci., vol. 22 , no. 2 , pp. 546-556, 2018

[8] P. Larrañaga, D. Atienza, J. Diaz-Rozo, A. Ogbechie, C. PuertoSantana, and C. Bielza, "The fourth industrial revolution," in Industrial Applications of Machine Learning, CRC Press, 2018.

[9] F. Piazolo, V. Geist, L. Brehm, and R. Schmidt, Innovations in Enterprise Information Systems Management and Engineering, vol. 285. Cham: Springer International Publishing, 2017.

[10] I. Schönreiter, "Significance of Quality 4.0 in post merger process harmonization," in International Conference on Enterprise Resource Planning Systems, 2017, pp. 123-134.

[11] H. Hirsch-Kreinsen, "Digitization of industrial work: development paths and prospects," J. Labour Mark. Res., vol. 49, no. 1, pp. 114, Jul. 2016.

[12] D. Mourtzis, Development of skills and competences in manufacturing towards Education 4.0: a teaching factory approach. 2018.

[13] O. Staiculescu, "Quality and Social Responsibility: A Pathway to the Future," Procedia - Soc. Behav. Sci., vol. 109, pp. 241-245, Jan. 2014.

[14] ASQ, "Seeking Sustainable Success: ASQ Integrates Quality and Social Responsibility," $2009 . \quad$ [Online]. Available: http://asq.org/2009/05/iso-26000/seeking-sustainable-success-asqintegrates-quality-and-social-responsibility.pdf.

[15] E. Dell'Aquila, D. Marocco, M. Ponticorvo, A. di Ferdinando, M. Schembri, and O. Miglino, "Soft Skills," in Educational Games for Soft-Skills Training in Digital Environments, Cham: Springer International Publishing, 2017, pp. 1-18.

[16] A. F. Hendarman and U. Cantner, "Soft skills, hard skills, and individual innovativeness," Eurasian Bus. Rev., vol. 8, no. 2, pp. 139-169, Jun. 2018.

[17] B. Motyl, G. Baronio, S. Uberti, D. Speranza, and S. Filippi, "How will change the future engineers' Skills in the Industry 4.0 framework? A questionnaire survey," Procedia Manuf., vol. 11, pp. 1501-1509, 2017.

[18] J. Antony, "What does the future hold for quality professionals in organisations of the twenty-first century?," TQM J., vol. 25 , no. 6 , pp. 677-685, Sep. 2013.

[19] R. Medina, "Upgrading yourself- technical and nontechnical competencies," IEEE Potentials, vol. 29, no. 1, pp. 10-13, Jan. 2010.

[20] A. N. Nasir, D. F. Ali, M. K. Noording, and M. S. Nordin, "Technical skills and non-technical skills: predefinition concept," in IETEC 2011, 2011, pp. 1-17.

[21] L. Fonseca, P. Domingues and J.G. Sá, "Leading quality in the $21^{\text {st }}$ century: profiles of quality and organizational excellence managers," Quality-Access to Success, vol. 18, no. 61, pp. 34-38., 2017. 